\title{
Research on the Present Situation and Countermeasures of the Integration of Urban and Rural Compulsory Education in Hubei Province
}

\author{
Guohua Zuo ${ }^{1}$, Lihua Wang ${ }^{2, *}$ \\ ${ }^{1}$ Academy of Fine Arts, Huanggang Normal University, Huanggang, Hubei, P.R. China, 438000 \\ ${ }^{2}$ Department of Business Administration Guangxi Technological College of Machinery and Electricity, \\ Nanning, Guangxi, P.R. China, 530007
}

king.ling@126.com

Keywords: urban and rural integration; compulsory education evaluation system; education funds

\begin{abstract}
This paper analyzes the policy background and reality of urban and rural education integration in China, combs the theory of urban and rural education at home and abroad, and points out its shortcomings. This paper expounds the present situation and existing problems in the administrative behavior of compulsory education in urban and rural areas in Hubei Province, the scale of schools, the contingent of teachers, the rate of meeting the standard of hardware facilities, the guarantee of educational funds, the system of supervision and evaluation, and so on, then froms the theoretical conception, teacher exchange system, "beautiful rural campus" establishment activity, "regional education cloud" information platform construction, teacher team construction of "turn, retreat, lead, compensate", and put forward the corresponding development strategy. It expected that the integrated development of compulsory education in the urban and rural areas of Hubei is enlightening.
\end{abstract}

\section{Overview of Research}

The idea of urban-rural integration has emerged in the last century. Since the reform and opening up, especially at the end of 1980s, due to various social and economic contradictions and present, the situation of segregated development between urban and rural areas has formed. This situation also affects the balanced development of urban and rural compulsory education, and is highly valued by government departments. The outline of the national medium- and long-term education reform and development plan (2010-2020) emphasizes "the promotion of equity as the basic education policy of the country", and puts forward "speeding up narrowing the gap between urban and rural areas and establishing a mechanism for the development of urban-rural integrated compulsory education". This is the first time that a national education development strategy of integrating urban and rural education. In addition, in 2016 has put forward. In 2000, the State Council issued and issued several opinions on the overall promotion of the reform and development of urban and rural compulsory education in the county, calling for speeding up the narrowing of the gap between urban and rural education and promoting education fairness in accordance with the goal of building a well-off society in an all-round way. We will comprehensively promote the reform and development of urban and rural compulsory education integration at the county level.

In recent years, all over the country in the process of promoting the integration of urban and rural education, of course, there are some shortcomings. For example, Jiangsu, Jiangxi, Henan and other provinces have made some achievements in the construction of urban and rural education integration, while Tianjin is in the forefront of urban and rural education integration. Domestic scholars have also published some academic papers; put forward their views on the integration of urban and rural education. For example, Zhou Xu and Zhao Wei-ling's book "Research on the Index system of Urban-Rural Education Integration in Chongqing" puts forward two aspects, five forms and twelve levels of the integration of urban and rural education in Chongqing. Yang Chun fang Bin's thesis "the present situation and system Innovation of promoting the Integration of Urban and Rural Education in Tianjin" analyzes the present situation of the integration of urban and rural 
education in Tianjin, and puts forward concrete reform measures for the system innovation.

In addition, Hubei's urban and rural education integration works have published one after another. Such as Li Jin qi, Yuan Xiao pang's article "several pairs of contradictory Relations in the course of the Development of Urban-Rural Education Integration: reflections on the practice of the Adjustment of Rural School layout" the article deeply reflects on the development of urban-rural education integration and the adjustment of rural school layout in China. Zhou Zhi lin's "the Theory and practice of Urban-rural Education Integration" expounds in detail the ideological origin, concept and countermeasures of urban and rural education. Yang Zhi tao's paper "Urban-rural educational integration should exert its power on the word" equilibrium "discusses the present situation and strategy of Ezhou's urban-rural educational integration. Yang Jin fu's the implementation of "Seven as a whole" to promote the Integration of Urban and Rural Education. This paper briefly describes the background and innovative contents of the implementation of Urban-Rural Education Integration in Ezhou. In addition, some other experts and scholars have also made a more detailed discussion on the integration of urban and rural education, and some leading experts in education departments have put forward their own views and opinions. From the works published by the above experts and scholars, either the integration of urban and rural compulsory education in Hubei is not discussed, or although there is some discussion, most of them are scattered implementation methods or experience summary, and there is no relatively stable research system. Foreign experts and scholars have also expressed their views on the difference between urban and rural education in China. U.S. economist Eli Maskin says the big gap between the rich and the poor in China is due to the lack of access and opportunities for low-income people to get hi-tech jobs, which can change by providing a fair education. James Heckman, the Nobel laureate in economics, pointed out that there was a serious imbalance in the investment in education in various regions of China. Foreign experts mainly comb the differences between urban and rural education in China in macro theory, but lack of empirical research.

In view of this, the theoretical research and empirical analysis on the integration of urban and rural compulsory education in Hubei is still lacking, and the purpose of this paper is to make up for the deficiency in this respect.

\section{Status of Development}

\subsection{Administrative acts and practical activities based on the integration of urban and rural compulsory education.}

The integration of urban and rural compulsory education in Hubei Province lags behind, but in recent years, the province has also achieved certain results in promoting the integration of urban and rural education. For example, as a pilot city of urban and rural integration in Hubei Province, E zhou has implemented "seven overall plans" and promoted the integration of urban and rural education. In 2013, the three pilot districts of urban and rural education integration reform in this city passed the acceptance inspection, which effectively promoted the balanced development of education. Hubei Qian jiang has implemented the "regional integration" mode of "double joint as the main body, double support as the supplement, double superior as the foundation, double match as the guarantee", and the urban and rural areas share the high-quality educational resources.

In recent years, Huang gang, Hubei Province, has vigorously promoted educational collectivization in order to explore the adjustment of school layout, financial investment, teacher allocation, and so on, in order to practice the integration of urban and rural areas, and to ensure the right of migrant children to receive education. Speed up the "compulsory education school standardization construction project" and launch the "beautiful rural campus" to create activities. Speed up the establishment of the "Demonstration County for balanced Development of compulsory Education", explore the pilot projects for the balanced development of compulsory education at high levels, and vigorously implement the "Education Information Construction Project", etc. In November 2013, the Huang gang Municipal Committee of the Communist Party of China. 2017, the city stressed the "look back" in the basic balanced development of compulsory 
education in the education work meeting, and started the supervision and evaluation of the balanced development of compulsory education, and promoted a balanced development. From the conditions of running a school to the connotation of running a school, continue to promote the "comprehensive thinning" of the compulsory education project and speed up the narrowing of the gap between urban and rural schools. Wu xue also puts forward the concept of teacher mobility to promote the integration of urban and rural education, and the other counties have various measures to promote the integration of urban and rural education.

In April 2017 the General Office of the Hubei Provincial Government issued the "opinions of the Provincial people's Government on the implementation of the overall Promotion of the Reform and Development of Urban-Rural compulsory Education in the Counties", further strengthening The importance and urgency of the integration of urban and rural compulsory education in the province has been adjusted. The publication of the document for the integration of urban and rural education in Hubei Province played a role in promoting the flames.

Although the compulsory education in urban and rural areas in Hubei Province is in administrative behavior and practical activities, there are still some problems in the implementation, efficiency and innovation of activities.

\subsection{Changes in the size of compulsory education schools, the number of students and the number of teachers.}

In 2014, there were 5513 primary schools in the province, which reduced to 5378 in 2017 to 2.45\% in 2017. In 2014, there were 2011 junior high schools in the province and 2041 in 2017. The increase reached 597 thousand and 500 in 1.49\%.2014 primary school enrollment, 625 thousand in 2017, and 4.6\% in 2017. In 2014, 526 thousand and 200 students enrolled in 526 thousand and 200, increasing the province of 15.83\%.2014 years. There were 199 thousand and 200 full-time teachers in primary schools, up from 203 thousand and 300 in 2017. In 2014, there were 133600 full-time teachers in junior high school, and in 2017, there were 129000, a decrease of 3.44. [1]

It can seen from the above data that the number of primary schools in Hubei has been decreasing year by year in recent years, and the number of students and full-time teachers has increased in varying degrees. However, the number of junior middle school students increased slightly, especially the number of junior high school students increased significantly, but the number of full-time teachers in junior high school decreased. It shows that the distribution of compulsory education schools in this province continues to adjust, the educational resources are continuously integrated, the quality of compulsory education schools is constantly improved, and the scale of schools, the number of students and the number of teachers have all changed greatly. Compulsory education is to cluster, elite development.

Although the scale of compulsory education schools in Hubei is expanding, there are still some shortcomings in the top-level design of education, the establishment of "beautiful rural campus" and the flow of teachers.

\subsection{Complete hardware facilities and high compliance rate.}

According to the statistics of Hubei Provincial Education Department, by 2014, the construction area of primary school buildings in the province has reached 27.5239 million square meters, and the average building area of students has reached 8.57 square meters. The general secondary school building area of 41.1937 million square meters, the average building area of 17.95 square meters. Primary school, junior middle school sports stadium (library) area reach the standard school ratio is 85.111, 92.54. the proportion of sports equipment equipped to reach the school number is 84.96 to 93.2445; the music equipment standard school ratio is 83.860.91.94; the fine arts equipment is equipped to reach the standard school number ratio is 83.860.94; the fine arts equipment equips the equipment to reach the standard school number ratio respectively is $83.86 \%$. The standard school number ratio is 83.51 / 91.35, and the number of mathematical natural experimental instruments is 84.47 and 94.63.2015 respectively. The number of newly built (expanded, reformed) boarding canteens in rural compulsory education has reached 526, and the drinking water problem of 509 boarding school students has solved. [2] 
It is not difficult to see from the above data that the building area of Hubei compulsory education school enlarged to ensure that students have a spacious and comfortable learning environment. Sports, music, art equipment is more complete, help to improve the teaching level of compulsory education. The new canteen to solve the problem of drinking water greatly improved the living conditions of urban and rural schools. In recent years, the hardware facilities of compulsory education schools in Hubei Province have improved, the conditions for running schools have improved, and the rate of meeting standards is higher, which has created a good material condition for the equalization of compulsory education between urban and rural areas. However, there are still a lot of differences between urban and rural teaching equipment, advanced hardware facilities, etc. Question

\subsection{Implementation of the policy on the guarantee of funds for compulsory education.}

In order to implement the national compulsory education fund and guarantee policy, Hubei Province has been striving for more than 8.5 billion yuan of central financial subsidy in 2014, reaching the standard of 600 yuan for primary school students and 800 yuan for junior high school students. It is also the first time that public funds for boarding schools in rural areas have subsidized. Reach the standard of 200 yuan per student. Students receiving compulsory education in rural areas will continue to be exempted from school fees, textbooks will be distributed free of charge, and living allowances will be granted to boarding students in financial difficulties. Urban compulsory education students exempt from school fees, according to the standard of 210 yuan for pupils and 240 yuan for junior high school students. Urban compulsory Education for accepting the Children of migrant Workers in cities School awards and subsidies have ensured the equal right of the children of urban and rural compulsory education migrants to receive education. [3] Starting from the spring semester of 2016, Hubei Province will unify the standard quota of public expenditure for students of urban and rural compulsory education schools, starting from the spring semester of 2017. Unifying the policy of "two exemptions and one supplement" for students of compulsory education in urban and rural areas. [4] From the background of the policy, the funds guarantee for compulsory education in urban and rural areas is gradually moving towards standardization and unification, and a relatively perfect mechanism of funding guarantee for compulsory education has gradually established.

Urban and rural compulsory education in Hubei Province has greatly increased in terms of funding input and policy implementation, but there are deficiencies in the allocation of funds. The theoretical construction of compulsory education, the creation of characteristic activities, the evaluation and evaluation of compulsory education, Teacher exchange and other aspects of the lack of capital allocation.

\subsection{The system of supervision and evaluation of the balanced development of compulsory education should promote.}

In 2012, the Education Supervision Office of the Hubei Provincial people's Government and the Provincial Education Department revised the "Supervision and Evaluation Program for balanced Development of compulsory Education at the County level in Hubei Province," in order to set up the basic conditions for running compulsory education schools at the county level. The people's governments at the county level have formulated evaluation indicators for the balanced development of compulsory education, and set monitoring indicators for the inter-school balance of compulsory education at the county level. In 2015, 92 counties (cities and districts) passed the education assessment in the province. Accounting for $82 \%$, through the supervision of the Ministry of Education to identify 72 counties (cities, districts), the first. The county governments and the administrative departments of education issue timely notice of supervision and evaluation, and all supervision and evaluation the evaluation work is progressing steadily. The provincial government education supervision office also commended 15 advanced counties (cities, districts, 15 demonstration counties) respectively. The balanced development of compulsory education in 33 counties (cities and districts) that did not receive provincial education evaluation monitored emphatically, urged to promote construction by evaluation, and suggestions for rectification and 
reform were forward in view of outstanding difficulties and weak links. [5]

The implementation of the supervision and evaluation system for the balanced development of compulsory education in Hubei will further promote the balanced development of compulsory education at the county level, promote the equalization of the provision of compulsory education teachers, and unify the standards of infrastructure, improving the quality of education and teaching plays an inestimable role. However, there are still some shortcomings, such as the transparency of the evaluation process, the extent to which information is public and disseminated, the strength of rectification after the evaluation, and the sense of accountability, and so on. These problems have more or less become the fetters of the overall development of urban and rural compulsory education in Hubei.

\section{Countermeasures}

Because of the more rural areas in Hubei, the integration of urban and rural compulsory education started late, and there are still a lot of problems in the renewal of the educational concept, the "help" of compulsory education, the creation of "beautiful rural campus", the construction and flow of teachers and the information of Education. Based on this, the author puts forward the following countermeasures.

\subsection{To draw on the valuable experience in the development of compulsory education in Hubei Province, and put forward a theoretical conception.}

This paper investigates the present situation of the integration of urban and rural education in Hubei Province, grasps the data of the balanced development of compulsory education at the present stage, draws on the valuable experience in the process of development, clarifies the shortcomings in the process of development and puts forward corresponding solutions. It will help speed up the balanced development of compulsory education in Hubei.

Combined with the views of education departments, schools and related functional departments, outline the top-level design of urban and rural compulsory education development. Deeply study the meeting, document and spirit of the local urban-rural education integration, understand the connotation of the document, form a relatively stable development plan, and sort out the theoretical articles on the integration of urban and rural education. The theoretical conception of promoting the integration of urban and rural education in Hubei Province is the primary task of promoting the equity of education in urban and rural areas.

\subsection{To promote the work of "helping and taking care of" compulsory education and to implement the system of teacher exchange.}

In order to improve the weakness of teachers in rural compulsory education, the purpose of this paper is to develop rural and urban school education in a balanced way, and to promote rural school education with "help and support". Taking rural teachers as the key object of "national education", combining with the rural education of normal college students, the city and county cities, and carrying out the system of teacher exchange vigorously, more and more high-quality teachers will go to the countryside. At the same time, it is necessary to put an end to the phenomenon that teachers' exchange turns into education officials and school leaders punish "disobedient" teachers. To promote the De-administration of Education and ensure the teacher's waiting [6] Let the system of teacher exchange and rotation become a beneficial supplement to the balanced development of compulsory education in urban and rural areas.

\subsection{To launch the "beautiful rural campus" to help the balanced development of compulsory education.}

The construction of "beautiful rural campus" is the concrete action of constructing "beautiful China" and "happy Hubei" in the educational system. [7] We should put forward concrete implementation plans for the creation of "beautiful rural campus" and increase the support for the weak rural schools. Carry out extensive publicity; strengthen the construction of rural school 
infrastructure and cultural soft power; promote campus stability and harmonious development of interpersonal relations; solve the school weariness, psychological and social problems of rural left-behind children; further reduce urban and rural areas, the gap between schools speeds up the balanced development of compulsory education.

\subsection{To promote the construction of the "three links and two platforms" and the "Regional Education Cloud" service platform.}

Speed up the "three links and two platforms" education information process in urban and rural schools, and gradually realize the "regional education cloud." On the one hand, on the one hand, the basic solution of broadband network school pass, at the same time, we should take high quality resources class pass as the key content of urban and rural schools information. On the other hand, it is necessary to vigorously promote the network learning space of urban and rural schools, accelerate the construction of public service platform of educational resources and public service platform of education management. Gradually set up a safe, stable and efficient "education cloud" service platform to realize the cooperative office and resource sharing in the region.

\subsection{To do a good job in "turning, retreating, leading and compensating" in the construction of the teaching staff, and optimizing the educational resources in urban and rural areas.}

With the steady development of urban-rural integration, the former mechanism of teacher training for compulsory education in urban and rural areas has been unable to adapt to the new situation, in order to meet the internal needs of the construction of the contingent of compulsory education teachers in urban and rural areas and the changes in the external environment. It is necessary to do the following work well: first, to change the qualified private education in time. second, to dismiss substitute teachers who fail to meet the teaching standards, and to send teachers from rural schools to go out for training and further study; Third, it is necessary to guide the fresh graduates of normal university major to fill the ranks of teachers in rural schools, and do a good job in the docking between teacher training and practical needs. Fourth, we should carry out the project of "hand in hand" to promote rural schools in urban areas. A number of urban school backbone teachers were sent to the countryside to give lectures and implement economic subsidies, which were regarded as conditions for teachers to advance to participate in social practice.

\section{Conclusion}

The compulsory education in urban and rural areas in Hubei Province has changed year by year. It has made unprecedented achievements in terms of administrative behavior, practical activities, school scale, infrastructure, teaching staff, financial support, evaluation system, and so on. However, there are some shortcomings, such as the system of teacher exchange still needs to be improved, the process of information construction needs to be improved, the activity of creating beautiful rural campus is not bright enough, and the construction of teachers' team needs to be strengthened. In view of the above problems, the author puts forward the corresponding countermeasures, hoping to promote the integration of urban and rural compulsory education in Hubei.

\section{Acknowledgements}

This article is the stage achievement of Hubei Province Education Science Planning 2017 key topic "Hubei Urban-Rural compulsory Education Integration Development Strategy Research", subject No.: 2017 GA 038.

\section{References}

[1] Zhang Wang. Research on the Integration of Urban and Rural compulsory Education. Educational Science Press.

[2] Outline of the Twelfth Five-Year Plan for National Economic and Social Development of the 
People's Republic of China [M]. Beijing: people are Publishing House.

[3] Zhang Pi f. An effective approach to the Integration of Urban and Rural compulsory Education in Sichuan Province [J]. Education and Teaching Research.

[4] Z X l. Analysis on the difference between City, Township and region of Education in our country [J]. The monthly price is in $2007 / 04$.

[5] Talent Resources Development Group of Sichuan Science and Technology Advisory Group. Problems and suggestions on the Equity of Urban and Rural Education in Sichuan Province [J]. Decision-making consultation Newsletter: 2007 / 01.

[6] Si X h. To optimize the allocation of educational resources and promote the quality development of compulsory education in western rural areas [J]. Educational Research in 2009.

[7] Wang K q. On the Integration of Urban and Rural Education [J]. General education research 1995 1: 6-8.

[8] He Yi f. To promote the integration of urban and rural education and promote the balanced development of education in Chengdu [J]. Educational Science Forum 2006.

[9] F Bo. Integration of Urban and Rural Education and harmonious Development [J]. Chongqing Social Sciences, 2008.

[10] Cha You l. New thoughts on the Integration of Urban and Rural Education [J]. The Chinese Journal of Education is in 2006.

[11] H Jin t. Work hard to make education to the satisfaction of the people [N]. People's Daily, 2 Educational Researches, 2006 and (1).

[12] The Rise of China's Educational Reform and Development (1978 - 2008): 158. Reform and Reform of China's Educational Reform and Development Course: The Rise of Educational Power (1978 - 2008).

[13] Beijing: Science Education Press, 2008 (Version 1): 342. 